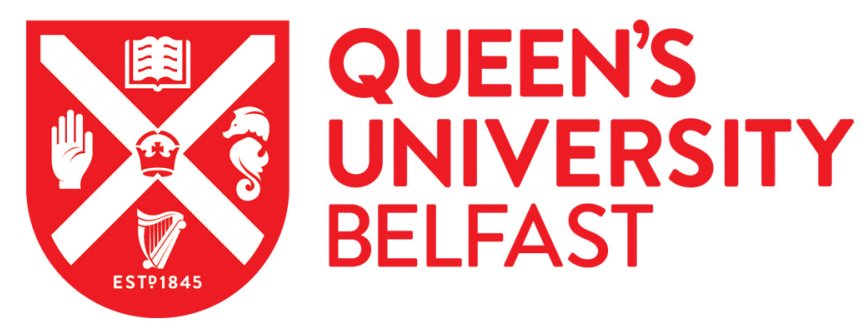

\title{
Psychological distress among family carers of oesophageal cancer survivors: the role of illness cognitions and coping
}

Dempster, M., McCorry, N. K., Brennan, E., Donnelly, M., Murray, L. J., \& Johnston, B. T. (2011). Psychological distress among family carers of oesophageal cancer survivors: the role of illness cognitions and coping. Psychooncology, 20(7), 698-705. https://doi.org/10.1002/pon.1760

Published in:

Psycho-oncology

Document Version:

Peer reviewed version

Queen's University Belfast - Research Portal:

Link to publication record in Queen's University Belfast Research Portal

Publisher rights

Copyright 2010 John Wiley \& Sons, Ltd

javascript:void(0)

This work is made available online in accordance with the publisher's policies. Please refer to any applicable terms of use of the publisher.

\section{General rights}

Copyright for the publications made accessible via the Queen's University Belfast Research Portal is retained by the author(s) and / or other copyright owners and it is a condition of accessing these publications that users recognise and abide by the legal requirements associated with these rights.

Take down policy

The Research Portal is Queen's institutional repository that provides access to Queen's research output. Every effort has been made to ensure that content in the Research Portal does not infringe any person's rights, or applicable UK laws. If you discover content in the Research Portal that you believe breaches copyright or violates any law, please contact openaccess@qub.ac.uk. 
Psychological distress among family carers of oesophageal cancer survivors: the role of illness cognitions and coping

Martin Dempster ${ }^{1}$, Noleen K. McCorry ${ }^{1}$, Emma Brennan ${ }^{1}$, Michael Donnelly ${ }^{2}$, Liam J. Murray $^{2}$, Brian T. Johnston ${ }^{3}$

${ }^{1}$ School of Psychology, Queen's University Belfast, N. Ireland

${ }^{2}$ School of Medicine \& Dentistry, Queen's University Belfast, N. Ireland

${ }^{3}$ Royal Group of Hospitals, Belfast Health \& Social Care Trust, N. Ireland

Acknowledgements:

This research was supported by a grant from Action Cancer, Northern Ireland and facilitated by David Kirby and staff at the Oesophageal Patients' Association UK

Corresponding author:

Martin Dempster

School of Psychology

Queen's University Belfast

University Road

Belfast

Northern Ireland

UK

BT7 1NN

Tel: +442890975547

Fax: +44 2890664144

Email: m.dempster@qub.ac.uk

Running head: Psychological distress in carers of oesophageal cancer survivors

There are no conflicts of interest for any authors 


\begin{abstract}
Objective: The research aimed to determine the extent to which illness cognitions and coping explain psychological distress (fear of cancer recurrence, anxiety and depression symptoms) among family carers of survivors of oesophageal cancer.

Methods: Carers of patients registered with the Oesophageal Patients' Association in the UK were mailed a questionnaire booklet containing questions about medical and demographic variables, the Illness Perception Questionnaire-Revised, the Cancer Coping Questionnaire, the Concerns about Recurrence Scale and the Hospital Anxiety and Depression Scale.

Results: Complete responses were received from 382 family carers (75\% male; mean (SD) age $=62$ (10.91) years). Regression models indicated that the variables measured could explain between $35 \%$ and $49 \%$ of the variance in psychological distress among carers. Illness cognitions (particularly perceptions of the cause of, consequences of and personal control over oesophageal cancer and the carer's understanding of the condition) explained the majority of this variance. Positive focus coping strategies were also found to be important in explaining psychological distress.

Conclusion: The results of this study are consistent with previous research demonstrating that illness cognitions are significant correlates of adaptive outcomes, thereby suggesting that cognition-based interventions could potentially be effective in minimizing emotional distress among family carers of oesophageal cancer survivors.
\end{abstract}

Keywords: Cancer; oncology; oesophagus; carers; depression; anxiety 


\section{Introduction}

The psychological distress of carers of people with chronic illness is an under-researched area [1]. Little research attention has been paid to carers' psychological distress, relative to the focus on the distress of the person with a chronic physical illness. Yet, the research evidence that exists suggests that the psychological health of carers is an important area for investigation. For example, carers experience significantly higher levels of depression than non-carers [2]. Therefore, it is important to model the factors that contribute to psychological distress among carers. However, no published research has examined the factors associated with symptoms of anxiety and depression among carers of oesophageal cancer survivors.

Oesophageal cancer is the ninth most common form of cancer in the UK [3] and the incidence of oesophageal adenocarcinoma has been increasing for several decades [4]. Symptoms of oesophageal cancer include: difficulty in swallowing (dysphagia); unexplained weight loss; pain in the form of pressure or a burning sensation as the food goes down the oesophagus; hoarseness or a chronic cough; vomiting; hiccups. Overall the prognosis for oesophageal cancer is poor, with the 5 year survival rate currently at $8 \%$, although survival rates are increasing and are higher among people who are able to have an oesophagectomy [3].

This prognosis is an obvious potential cause of distress for both the patient with oesophageal cancer and their family carer. Furthermore, the potential consequences of living with oesophagectomy, such as difficulty eating and regurgitation of food can impact on the quality of life of oesophageal cancer survivors $[5,6]$ and their family carers. Although there are commonalities between the experience of caring for someone with one type of cancer and caring for someone with another type of cancer, there are unique difficulties faced by people depending on the location of their cancer and therefore, unique difficulties faced by those who care for these people [7]. In the case of oesophageal cancer, the poor survival rates and the unique problems experienced after oesophagectomy, which can impact adversely on social functioning [8], suggest that the experience of caring for a survivor of oesophageal cancer will be a qualitatively different experience from caring for people with another type of cancer or chronic illness [9]. Consequently, it would be inappropriate to assume that the factors influencing psychological distress among those caring for oesophageal cancer survivors would be the same for people caring for survivors of other cancers.

A potentially useful theoretical basis for modelling the determinants of psychological distress may be found in Leventhal's Self-Regulatory Model [10]. Leventhal's Self-Regulatory Model (SRM) suggests that when an individual is confronted with symptoms of an illness or condition, they will attempt to assign meaning to this illness by accessing their cognitions about the illness. These illness cognitions will be influenced by the individual's emotional state and their emotional state will be influenced by their perceptions of the illness. The SRM proposes that, in an effort to restore normal functioning, individuals will develop coping strategies (based on their illness cognitions and emotional state), which will then be evaluated in terms of their success in restoring equilibrium. In summary, the model is often operationalised as follows: illness cognitions are related to psychological distress but this path is mediated by coping strategies.

Research using quantitative methodologies has tended to focus on the illness cognitions component of the model and there is a growing body of research demonstrating strong relationships between illness cognitions and health outcomes [11]. Illness cognitions (as 
assessed by the Illness Perception Questionnaire-Revised [12]) are mental representations of illness by the individual within eight domains: identity, time line (acute/chronic), time line (cyclical), personal control, treatment control, consequences, cause and illness coherence. Illness cognitions have been shown to be associated with adjustment to caring for a relative with an eating disorder [13] or a relative with schizophrenia [14].

Previous research among carers of people with cancer has generally shown that coping strategies are an important determinant of psychological distress, with psychological distress increasing as more maladaptive coping strategies are employed by carers [15]. For example, carers of people with head and neck cancer who engage in a passive coping style are more likely to be distressed [16]; and carers of women with breast cancer who engage in avoidant coping strategies are more likely to have a poor quality of life [17]. However, no previously published research has examined the potential mediating role of coping in the relationship between illness cognitions and psychological distress. In fact, although there is a body of research linking carers' perceptions of the caregiving role to health-related outcomes [eg. $18,19]$, there is no previously published research which has examined the relationship between illness cognitions and psychological distress among family carers of cancer survivors.

Therefore, the present research aims to: determine the extent to which illness cognitions explain psychological distress (fear of cancer recurrence, anxiety and depression symptoms), relative to demographic and biomedical variables, among family carers of survivors of oesophageal cancer; and examine the influence of the potential mediating variables (coping strategies) in these relationships.

\section{Method}

Participants were recruited via the Oesophageal Patients' Association (OPA) UK database. The OPA is a support group formed to help patients and their families cope with the difficulties arising from the treatment associated with oesophageal cancer. All patients on the OPA database were mailed a questionnaire booklet and asked to forward this booklet to someone they identified as a "carer". The questionnaire booklet contained items relating to demographic information (sex, age and their relationship to the cancer survivor they cared for), medical history of the cancer survivor (time since diagnosis and number of comorbidities) and the following questionnaires:

The Hospital Anxiety and Depression Scale (HADS) [20]. This is a 14 item scale which is divided into two dimensions - anxiety ( 7 items) and depression ( 7 items). Respondents choose one from four responses to each item. Their responses are then summed within dimensions and a total score for each dimension is obtained, with higher scores representing higher levels of anxiety and depression. Scores for the anxiety dimension and the depression dimension can be categorised as follows: 0-7: normal, 8-10: mild, 11-14: moderate, 15-21: severe. The HADS has been validated among a range of groups, including primary care patients and the general population [21] and has been used previously among carers of people with cancer [eg. 22].

The Concerns About Recurrence Scale - Part 1 (CARS - 1) [23]. This is a 4 item scale which provides a total score assessing fear of cancer recurrence. It was originally designed for women with breast cancer and has evidence for validity and internal consistency [23]. Higher 
scores on the scale indicate higher levels of fear of recurrence. The CARS has been used previously among carers of people with cancer [24].

The Cancer Coping Questionnaire (CCQ) [25]. This is a 21 item questionnaire which assesses 5 dimensions: reflection/relaxation coping, positive focus, diversion, planning and use of interpersonal support. Higher scores on each scale indicate that this coping strategy is used more often. Psychometric properties are sound [25].

Illness Perception Questionnaire - Revised (IPQ-R) [12]. This questionnaire was used to assess the following illness cognitions: time line acute/chronic, time line cyclical, personal control, treatment control, consequences, cause and illness coherence. Higher scores on the personal control and treatment control scales indicate that the carer has a stronger belief in the effectiveness of their ability or the treatment to control the symptoms of oesophageal cancer; higher scores on the consequences scale suggests that the carer perceives more severe consequences of oesophageal cancer; higher scores on the illness coherence scale indicates that the carer has a clearer understanding of the condition; higher scores on the timeline acute/chronic and timeline cyclical scales indicate a stronger belief that the condition is chronic (rather than acute) and goes through cycles of getting better and worse rather than remaining stable.

In order to reduce the 18 items which measure the carer's perceptions of the causes of oesophageal cancer into more meaningful and interpretable scales, a factor analysis of these items was conducted. The authors of the IPQ-R recommend factor analyzing these items within each sample in order to determine the most appropriate grouping of these items for the sample under consideration. The data was considered suitable for factor analysis $(\mathrm{KMO}=$ 0.89; Bartlett's $\left.\chi^{2}=1896.69, \mathrm{p}<.001\right)$. Therefore, a principal components analysis was conducted, with oblimin rotation and the items were found to load on 3 factors, which were labelled emotional causes (e.g. stress or worry), behavioural causes (e.g. smoking or alcohol) and externalised causes (e.g. hereditary or a virus). The eigenvalues for the 3 factors were $4.56,1.78$ and 1.57 respectively and the factors explained $44 \%$ of the total variance. Higher scores on the cause scales indicate a stronger belief that this was a cause of the oesophageal cancer. The IPQ-R has sound psychometric properties, with evidence for construct, discriminant and predictive validity and for internal and test-retest reliability [12].

Following the strategy of Barrowclough and colleagues [26], the illness cognitions of personal control, consequences and illness coherence were addressed from 2 perspectives. Firstly, carers were asked about their perceptions of their personal control over oesophageal cancer, the consequences of the condition for their lives and their understanding of the condition. Secondly, carers were asked about their perceptions of the personal control that the survivor could exert over the condition, their perceptions of the effect of the condition on the survivor's life and their perceptions of the survivor's understanding of the condition.

Ethics approval was obtained from the University Ethics Committee.

Statistical Analysis

To address the study aim, Pearson's correlation coefficients were calculated for the relationships between the illness cognitions and psychological distress variables and between the coping strategies and psychological distress variables. Subsequently, 3 hierarchical least squares regression analyses were conducted - 1 for each outcome (anxiety symptoms, 
depression symptoms and fear of recurrence). The outcome variables were treated as continuous scores, with a higher score indicating higher levels of distress. Medical and demographic variables were entered into the regression models in block 1 ; illness cognitions were entered in block 2; and the coping variables were entered in block 3 . In this way, we were able to determine the additional contribution to the explanation of variance in the outcome variable made by each block of variables. Additionally, this strategy allowed us to examine whether the addition of the coping variables changed the regression coefficients of the illness cognition variables. If so, this would suggest that coping variables could be playing a mediating role in the model and would highlight the need for further analyses to explore this potential mediation. A backward selection method was used in all regression analyses to provide a more parsimonious solution.

\section{Results}

A total of 382 carers provided complete data on all the questionnaires. Respondents were, on average, 62 years old $(\mathrm{SD}=10.91)$; approximately $75 \%(257 / 382)$ of the carers were female and $94 \%$ were the spouse or partner of the person they cared for (with the remaining $6 \%$ being other family members). The person they cared for had been diagnosed with oesophageal cancer for a median (interquartile range) time of $46(19-81)$ months prior to completing the questionnaire.

Descriptive statistics are presented in Table 1. In terms of categorization of the HADS scores, $20 \%$ of carers reported mild levels of anxiety and $15 \%$ reported mild levels of depression; $19 \%$ reported moderate levels of anxiety and $8 \%$ reported moderate levels of depression; $11 \%$ reported severe levels of anxiety and $2 \%$ reported severe levels of depression. This indicates that at least $30 \%$ of the respondents are probably experiencing anxiety disorder. The data in Table 1 suggest that, on average, respondents perceive oesophageal cancer to be chronic, caused mainly by environmental events and they expect it to have adverse consequences for the survivor's life but not for their life. The carers report having a reasonably good understanding of oesophageal cancer and they believe that both the survivor and the medical profession can control the condition but the carers perceive themselves to have less control over it.

Correlations between the illness cognitions and the psychological distress measures are shown in Table 2. The correlations indicate that the more strongly carers believe that they understand the condition, or the more they believe that the survivor's condition can be controlled by treatment or the survivor's personal behaviour, then the lower the carer's psychological distress (particularly depressive symptomatology). However, if the carer feels that the survivor does not understand his/her condition, then the carer's psychological distress (particularly depression) is more likely to be high. The carers' psychological distress also increases as their belief becomes stronger that severe consequences (for both the survivor and the carer) will result from the survivor's condition and the more they believe that the survivor's medical condition follows a cyclical pattern.

The reflection/relaxation, diversion and interpersonal coping factors demonstrate the strongest correlations with psychological distress and the more a carer reports engaging in any of these 3 coping strategies, the higher their reported psychological distress (see Table 2).

When regression models were generated, conclusions about the statistical significance of the regression coefficients for the medical/demographic variables and illness cognitions were not 
influenced by the addition of the coping variables. This suggested that coping strategies were not playing a mediating role in the model and therefore the final regression model only is presented in each case.

The regression model specified in Table 3 explained $48 \%$ of the variance in levels of anxiety (adjusted $\left.\mathrm{R}^{2}=47 \% ; \mathrm{F}(8,370)=42.654, \mathrm{p}<.001\right)$. The medical and demographic variables contributed $5 \%$ of the variance explained and the illness cognitions contributed an additional $27 \%$; with the coping variables contributing the remaining $16 \%$.

The regression model specified in Table 4 explained $40 \%$ of the variance in levels of depression (adjusted $\mathrm{R}^{2}=39 \% ; \mathrm{F}(9,354)=26.225, \mathrm{p}<.001$ ). The medical and demographic variables contributed $1 \%$ of the variance explained and the illness cognitions contributed an additional 33\%; with the coping variables contributing the remaining $6 \%$.

The regression model specified in Table 5 explained 35\% of the variance in levels of fear of recurrence (adjusted $\mathrm{R}^{2}=33 \% ; \mathrm{F}(9,351)=20.550, \mathrm{p}<.001$ ). The medical and demographic variables contributed $8 \%$ of the variance explained and the illness cognitions contributed an additional $21.5 \%$; with the coping variables contributing the remaining $5.5 \%$.

\section{Discussion}

No published research exists which has examined the role of illness cognitions and coping strategies in psychological distress among carers of survivors of oesophageal cancer (using the Self-Regulatory Model as a theoretical framework). This paper aimed to address that gap.

Psychological distress in this study was defined as anxiety, depression and fear of recurrence. Our data indicates that a sizeable proportion of carers are likely to be experiencing clinically significant levels of anxiety and/or depression. In terms of psychological distress, respondents in the sample appeared to be at greatest risk of symptoms which represent anxiety disorder. The anxiety and depression scores in this sample are higher than those found for carers of people with Alzheimer's Disease [27]; lower than those found for carers of people with a brain tumor [28] or carers of people with cancer in their final year of life [29] and similar to those found for carers of people with other head and neck cancers [24].

Regression analysis suggested that the variables under investigation were able to explain a considerable proportion of the variance in psychological distress. Psychological distress can be explained, to some degree, by the carer's age. However, after controlling for medical and demographic variables, the carers' illness cognitions and coping strategies contributed the majority of explained variance in anxiety, depression and fear of recurrence.

In particular, psychological distress is lower among carers who feel that they have a good understanding of oesophageal cancer and who believe that the oesophageal cancer has less serious consequences for their life. It is possible that these two cognitions are related and that those carers who believe that they have a good understanding of oesophageal cancer will also have appropriate perceptions about the effect of this condition on their lives. This highlights the importance of effective and appropriate communication with carers. Although a discussion about oesophageal cancer and its prognosis can be a delicate subject to tackle and there is ongoing debate in the literature about the benefits of having this type of discussion with patients [30], this is an important subject to address with carers. Yet, it is clearly a 
subject which must be addressed in an appropriate manner, where the content and nature of the communication often needs to be individualised [31].

In addition, carers with a stronger belief that the person they care for has personal control over the oesophageal cancer are less likely to experience psychological distress and a carer who believes that the oesophageal cancer was caused by external environmental events rather than the survivor's personal behaviour is also less likely to experience psychological distress. Again, issues of cause and control could be addressed in the first instance by informationgiving approaches. However, research suggests that addressing these cognitions more directly in an attempt to restructure them (via techniques such as those advocated in cognitive behavioural therapy) will be more beneficial to psychological health than providing education or general counselling $[32,33]$.

Additionally, maintaining a positive focus appears to minimize anxiety and depression symptoms, whereas spending more time attempting to divert yourself from thinking about oesophageal cancer are associated with increased levels of anxiety and depression. This finding fits with previous research conducted among carers of cancer survivors, which suggests that avoidant coping strategies are associated with higher levels of psychological distress [16,17]. For fear of recurrence and anxiety, one of the strongest covariates in the model was interpersonal coping. The result here suggests that carers who are more likely to engage in this type of coping are also more likely to report high levels of anxiety and fear of recurrence. The finding suggests a need for carers to find alternative sources of social support as a coping mechanism, as they do not derive a benefit from seeking support from the oesophageal cancer survivor. Previous research among family carers of people with lung cancer indicates that interpersonal support is important in psychological adaptation, but that carers need to be listened to by someone who can facilitate emotional expression [34]. Perhaps for the carer, the cancer survivor is not an appropriate person to fulfil this need, or perhaps the carer does not expect or ask for this level of support from the cancer survivor, as other research indicates that they place the needs of the survivor above their own [35]. Fundamentally, it seems that the relationship between interpersonal coping and psychological health of carers may be a complex one, with compatibility of cognitive style between carer and survivor being particularly important. For example, carers with a high need for cognition who have a partner with a high need for cognition are more likely to benefit from interpersonal communication with their partner than carers in a relationship where the need for cognition is incongruent between them and their partner [36].

In relation to Leventhal's Self-regulatory Model, the results support the hypothesis that family carers' personal beliefs about oesophageal cancer play a significant role in their adjustment, even when the effects of medical and demographic variables are taken into account. However, there was little evidence to support the role of coping as a mediator between illness cognitions and psychological distress.

The results of this study are consistent with previous research demonstrating that illness cognitions are significant correlates of adaptive outcomes among patient groups [37-39] thereby suggesting that cognition-based interventions could potentially be effective in minimizing emotional distress. However, longitudinal research is required to examine the relationship between changes in cognitions and changes in psychological distress, prior to an investment in an intervention trial. 
A potentially important limitation of the findings in this study is that the sample was drawn from a patient support group. Consequently, it may be the case that the sample in this study was biased towards those who are more informed about oesophageal cancer and more willing to engage with services and sources of support. This could mean that our assessments of psychological distress in the sample underestimate the levels of psychological distress in the population. On the other hand, it may be that carers who are more distressed are the people most likely to engage with patient support groups in an effort to seek help. There is some research to support this assertion [40]. However, in the absence of any population level information about carers of oesophageal cancer survivors, it is impossible to know whether the levels of psychological distress reported here are representative of that found in the population. Nevertheless, the focus in the present study is on an exploration of the relationships between variables and is not an attempt to establish definitive prevalence rates of distress.

Furthermore, the findings in the present research are limited by the assessment instruments employed. The psychometric properties of these instruments are sound, but for some of the instruments, an assessment of the psychometric properties has not been undertaken among a group of carers of cancer survivors. Additionally, the types of coping strategies included in our analyses are limited to those assessed by the CCQ, which does not cover a range of coping strategies as broad as that addressed by other instruments such as the COPE [41]. Nevertheless, the CCQ is more specifically focused on coping with cancer rather than coping in general.

In conclusion, it is important to note that most family carers of oesophageal cancer survivors are in good psychological health and do not require formal interventions. Nevertheless, similar to previous research [9] a sizeable proportion of family carers of oesophageal cancer survivors have clinically significant symptoms of psychological distress that can largely be explained by their perceptions of oesophageal cancer. These perceptions are modifiable and, therefore, appropriately tailored and targeted interventions could have beneficial effects for the quality of life of these carers. 
References

1. Mittelman M. Taking care of the caregivers. Curr Opinion Psychiat 2005; 18: 633-639.

2. Pinquart M, Sorensen S. Differences between caregivers and noncaregivers in psychological health and physical health. Psychol Aging 2003; 18: 250-267.

3. Cancer Research UK. UK Oesophageal Cancer Statistics. Available from URL: http://info.cancerresearchuk.org/cancerstats/types/oesophagus/index.htm [accessed November 5, 2009].

4. Botterweck AA, Schouten LJ, Volovics A, Dorant E, van den Brandt PA. Trends in incidence of adenocarcinoma of the oesophagus and gastric cardia in ten European countries. Int J Epidemiol 2000; 29: 645-654.

5. Lagergren P, Avery KNL, Hughes R, Barham CP, Alderson D, Falk SJ, Blazeby JM. Health-related quality of life among patients cured by surgery for esophageal cancer. Cancer 2007; 110: 686-693.

6. Watt E, Whyte F. The experience of dysphagia and its effect on the quality of life of patients with oesophageal cancer. Euro J Cancer Care 2003; 12: 183-193.

7. Vickery LE, Latchford G, Hewison J, Bellew M, Feber T. The impact of head and neck cancer and facial disfigurement on the quality of life of patients and their partners. Head Neck 2002; 25: 289-296.

8. McCorry NK, Dempster M, Clarke C, Doyle R. Adjusting to life after esophagectomy: The experience of survivors and carers. Qual Health Res 2009; 19: 1485-1494.

9. Donnelly M, Anderson LA, Johnston BT, Watson RGP, Murphy SJ, Comber H, McGuigan J, Reynolds JV, Murray LJ. Oesophageal cancer: Caregiver mental health and strain. PsychoOncol 2009; 17: 1196-1201.

10. Leventhal H, Meyer D, Nerenz D. The common sense representation of illness danger. Med Psychol 1980; 2: 7-30.

11. Cameron LD, Moss-Morris R. Illness-related cognition and behaviour. In Health Psychology, Kaptein A, Weinman J (eds.). BPS Blackwell: Oxford, 2004; 84-110.

12. Moss-Morris R, Weinman J, Petrie KJ, Horne R, Cameron LD, Buick D. The revised Illness Perception Questionnaire (IPQ-R). Psychol Health 2002; 17: 1-16.

13. Whitney J, Haigh R, Weinman J, Treasure J. Caring for people with eating disorders: Factors associated with psychological distress and negative caregiving appraisals in carers of people with eating disorders. Brit J Clin Psychol 2007; 46: 413-428.

14. Fortune DG, Smith JV, Garvey K. Perceptions of psychosis, coping, appraisals and psychological distress in the relatives of patients with schizophrenia: An exploration using self-regulation theory. Brit J Clin Psychol 2005; 44: 319-331. 
15. Rodrigue JR, Hoffmann RG. Caregivers of adults with cancer - multidimensional correlates of psychological distress. J Clin Psychol Medical Settings 1994; 1: 231-244.

16. Verdonck de Leeuw IM, Eerenstein SE, Van der Linden MH, Kuick DJ, de Bree R, Leemans CR. Distress in spouses and patients after treatment for head and neck cancer. Laryngoscope 2007; 117: 238-241.

17. Kershaw T, Northouse L, Kritpracha C, Schafenacker A, Mood D. Coping strategies and quality of life in women with advanced breast cancer and their family caregivers. Psychol Health 2004; 19: 139-155.

18. Kim Y, Loscalzo MJ, Wellisch DK, Spillers RL. Gender differences in caregiving stress among caregivers of cancer survivors. Psycho-Oncol 2006; 15: 1086-1092.

19. Kurtz ME, Kurtz JC, Given CW, Given BA. Depression and physical health among family caregivers of geriatric patients with cancer - a longitudinal view. Med Sci Mon 2004; 10: 447-456.

20. Snaith RP, Zigmond AS. The Hospital Anxiety and Depression Scale. Acta Psychiatrica Scand 1983; 67: 361-370.

21. Bjelland I, Dahl AA, Haug TT, Neckelmann D. The validity of the Hospital Anxiety and Depression Scale: An updated literature review. J Psychosom Res 2002; 52: 69-77.

22. Grov EK, Dahl AA, Moum T, Fossa SD. Anxiety, depression and quality of life in caregivers of patients with cancer in late palliative phase. Ann Oncol 2005; 16: 1185-1191.

23. Vickberg SM. The Concerns about Recurrence Scale (CARS): A systematic measure of women's fears about the possibility of breast cancer recurrence. Ann Behav Med 2003; 25: $16-24$.

24. Hodges LJ, Humphris GM. Fear of recurrence and psychological distress in head and neck cancer patients and their carers. Psycho-Oncol 2009; 18: 841-848.

25. Moorey S, Frampton M, Greer S. The Cancer Coping Questionnaire: A self-rating scale for measuring the impact of adjuvant psychological therapy on coping behavior. PsychoOncol 2003; 12: 331-344.

26. Barrowclough C, Lobban F, Hatton C, Quinn J. An investigation of models of illness in carers of schizophrenia patients using the Illness Perception Questionnaire. Brit J Clin Psychol 2001; 40: 371-385.

27. Cooper C, Katona C, Orrell M, Livingston G. Coping strategies, anxiety and depression in caregivers of people with Alzheimer's disease. Int J Geriatr Psychiatry 2008; 23:929-936.

28. Janda M, Steginga S, Langbecker D, Dunn J, Walker D, Eakin E. Quality of life among patients with a brain tumor and their carers. J Psychosom Res 2007; 63: 617-623. 
29. Burridge LH, Barnett AG, Clavarino AM. The impact of perceived stage of cancer on carers' anxiety and depression during the patients' final year of life. Psycho-Oncol 2009; 18: 615-623.

30. Hagerty RG, Butow PN, Ellis PM, Dimitry S, Tattersall MHN. Communicating prognosis in cancer care: A systematic review of the literature. Ann Oncol 2005; 16: 1005-1053.

31. Franssen SJ, Lagarde SM, van Werven JR, Smets EMA, Tran KTC, Plukker JTM, van Lanschot JB, de Haes HCJM. Psychological factors and preferences for communicating prognosis in esophageal cancer patients. Psycho-Oncol 2009; 18: 1199-1207.

32. Schwartz MD, Lerman C, Audrain J, Cella D, Rimer B, Stefanek M, Garber J, Lin TH, Vogel V. The impact of a brief problem-solving training intervention for relatives of recently diagnosed breast cancer patients. Ann Beh Med 1998; 20: 7-12.

33. Zimmermann T, Heinrichs N. Psychosocial interventions for women with genital cancers. Verhaltenstherapie \& Verhaltensmedizin 2006; 27: 125-141.

34. Richardson A, Plant H, Moore S, Medina J, Cornwall A, Ream E. Developing supportive care for family members of people with lung cancer: a feasibility study. Supportive Care Cancer 2007; 15: 1259-1269.

35. Thomas C, Morris SM, Harman JC. Companions through cancer: The care given by informal carers in cancer contexts. Soc Sci Med 2002; 54: 529-544.

36. Oh S, Meyerowitz BE, Perez MA, Thornton AA. Need for cognition and psychosocial adjustment in prostate cancer patients and partners. J Psychosoc Oncol 2007; 25: 1-19.

37. Dorrian A, Dempster M, Adair P. Adjustment to inflammatory bowel disease: The relative influence of illness perceptions and coping. Inflamm Bowel Dis 2009; 15: 47-55.

38. Heijmans M. The role of patients' illness representations in coping and functioning with Addison's Disease. Brit J Health Psychol 1999; 4: 137-149.

39. Rozema H, Völlnick T, Lechner L. The role of illness representations in coping and health of patients treated for breast cancer. Psycho-Oncol 2009; 18: 849-857.

40. Grande GE, Myers LB, Sutton SR. How do patients who participate in cancer support groups differ from those who do not? Psycho-Oncol 2006; 15: 321-334.

41. Carver CS, Scheier MF, Weintraub JK. Assessing coping strategies: A theoretically based approach. J Personality Soc Psychol 1989; 56: 267-283. 
Table 1: Descriptive statistics

\begin{tabular}{lccc}
\hline & $\begin{array}{c}\text { Potential } \\
\text { Midpoint }\end{array}$ & Mean (SD) & $\begin{array}{c}\text { Cronbach's } \\
\text { alpha }\end{array}$ \\
\hline Fear of Recurrence & 14 & $13.93(5.83)$ & 0.90 \\
HADS Anxiety & 10.5 & $7.83(4.92)$ & 0.89 \\
HADS Depression & 10.5 & $4.72(4.00)$ & 0.86 \\
CCQ Reflection/relaxation & 12.5 & $9.22(3.42)$ & 0.81 \\
CCQ Positive focus & 7.5 & $7.60(2.21)$ & 0.73 \\
CCQ Diversion & 7.5 & $6.42(2.23)$ & 0.77 \\
CCQ Planning & 7.5 & $7.01(2.51)$ & 0.72 \\
CCQ Interpersonal & 17.5 & $15.50(5.44)$ & 0.89 \\
IPQ Acute/chronic timeline & 18 & $22.85(4.77)$ & 0.84 \\
IPQ Cyclical timeline & 14 & $12.17(3.45)$ & 0.86 \\
IPQ Treatment control & 15 & $16.70(3.52)$ & 0.76 \\
IPQ Emotional cause & 15 & $12.47(3.86)$ & 0.78 \\
IPQ Behavioural cause & 12 & $10.03(3.69)$ & 0.76 \\
IPQ Externalised cause & 12 & $15.13(3.47)$ & 0.71 \\
IPQ Consequences (for patient) & 18 & $22.06(4.76)$ & 0.82 \\
IPQ Consequences (for carer) & 18 & $12.75(3.23)$ & 0.78 \\
IPQ Personal control (patient's control) & 18 & $18.86(4.68)$ & 0.82 \\
IPQ Personal control (carer's control) & 18 & $16.08(4.05)$ & 0.77 \\
IPQ Illness coherence (patient's understanding) & 15 & $19.03(3.88)$ & 0.88 \\
IPQ Illness coherence (carer's understanding) & 15 & $19.19(3.99)$ & 0.89 \\
\hline
\end{tabular}


Table 2: Correlations (and significance values) between illness cognitions and coping and psychological distress

\begin{tabular}{lccc}
\hline & Fear of & HADS & HADS \\
& Recurrence & Anxiety & Depression \\
\hline IPQ Acute/chronic timeline & $.084(.100)$ & $.090(.079)$ & $.099(.054)$ \\
IPQ Cyclical timeline & $.275(<.001)$ & $.248(<.001)$ & $.197(<.001)$ \\
IPQ Treatment control & $-.075(.144)$ & $-.172(.001)$ & $-.243(<.001)$ \\
IPQ Emotional cause & $.126(.014)$ & $.192(<.001)$ & $.166(.001)$ \\
IPQ Behavioural cause & $.095(.066)$ & $.124(.016)$ & $.113(.028)$ \\
IPQ Externalised cause & $-.073(.160)$ & $.029(.571)$ & $-.004(.942)$ \\
IPQ Consequences (for patient) & $.306(<.001)$ & $.338(<.001)$ & $.343(<.001)$ \\
IPQ Consequences (for carer) & $.475(<.001)$ & $.532(<.001)$ & $.512(<.001)$ \\
IPQ Personal control (patient's control) & $-.094(.065)$ & $-.178(<.001)$ & $-.238(<.001)$ \\
IPQ Personal control (carer's control) & $.034(.511)$ & $-.003(.951)$ & $-.085(.098)$ \\
IPQ Illness coherence (patient's understanding) & $-.150(.003)$ & $-.260(<.001)$ & $-.325(<.001)$ \\
IPQ Illness coherence (carer's understanding) & $-.119(.020)$ & $-.170(.001)$ & $-.245(<.001)$ \\
CCQ Reflection/relaxation & $.333(<.001)$ & $.478(<.001)$ & $.300(<.001)$ \\
CCQ Positive focus & $.068(.184)$ & $.066(.201)$ & $-.087(.088)$ \\
CCQ Diversion & $.327(<.001)$ & $.495(<.001)$ & $.340(<.001)$ \\
CCQ Planning & $.134(.009)$ & $.210(<.001)$ & $.115(.024)$ \\
CCQ Interpersonal & $.354(<.001)$ & $.401(<.001)$ & $.245(<.001)$ \\
\hline
\end{tabular}


Table 3: Regression Analysis with Carer Anxiety as the Outcome Variable

\begin{tabular}{lcrrr}
\hline & $\begin{array}{c}\text { Unstandardised } \\
\text { regression } \\
\text { coefficient }\end{array}$ & $\begin{array}{c}\text { Standardised } \\
\text { regression } \\
\text { coefficient }\end{array}$ & & $\mathrm{t}$ \\
\hline (Constant) & 8.039 & & 3.577 & $<.001$ \\
Age & -.081 & -.179 & -4.461 & $<.001$ \\
IPQ Personal control (patient's control) & -.124 & -.118 & -3.037 & .003 \\
IPQ Consequences (for carer) & .344 & .224 & 4.862 & $<.001$ \\
IPQ Illness coherence (patient's understanding) & -.113 & -.089 & -2.226 & .027 \\
CCQ Reflection/relaxation & .304 & .211 & 3.489 & .001 \\
CCQ Positive focus & -.495 & -.221 & -4.766 & $<.001$ \\
CCQ Diversion & .541 & .245 & 4.486 & $<.001$ \\
CCQ Interpersonal & .155 & .172 & 3.346 & .001 \\
\hline
\end{tabular}


Table 4: Regression Analysis with Carer Depression as the Outcome Variable

\begin{tabular}{lccrrr}
\hline & $\begin{array}{c}\text { Unstandardised } \\
\text { regression } \\
\text { coefficient }\end{array}$ & $\begin{array}{c}\text { Standardised } \\
\text { regression } \\
\text { coefficient }\end{array}$ & \multicolumn{1}{c}{$\mathrm{t}$} & $\mathrm{p}$ \\
\hline (Constant) & 7.502 & & 4.219 & $<.001$ \\
No. of months since diagnosis & -.006 & -.073 & -1.689 & .092 \\
IPQ Personal control (patient's control) & -.068 & -.080 & -1.672 & .095 \\
IPQ Treatment control & -.115 & -.101 & -2.108 & .036 \\
IPQ Illness coherence (carer's understanding) & -.179 & -.175 & -3.854 & $<.001$ \\
IPQ Consequences (for carer) & .399 & .324 & 6.789 & $<.001$ \\
IPQ Externalised cause & -.092 & -.079 & -1.830 & .068 \\
CCQ Reflection/relaxation & .147 & .126 & 2.032 & .043 \\
CCQ Positive focus & -.396 & -.219 & -4.528 & $<.001$ \\
CCQ Diversion & .334 & .189 & 3.146 & .002 \\
\cline { 2 - 3 }
\end{tabular}


Table 5: Regression analysis with fear of recurrence as the outcome variable

\begin{tabular}{lccrr}
\hline & $\begin{array}{c}\text { Unstandardised } \\
\text { regression } \\
\text { coefficient }\end{array}$ & $\begin{array}{c}\text { Standardised } \\
\text { regression } \\
\text { coefficient }\end{array}$ & $\mathrm{t}$ & $\mathrm{p}$ \\
\hline (Constant) & 14.422 & & 4.593 & $<.001$ \\
Age & -.091 & -.171 & -3.590 & $<.001$ \\
No. of months since diagnosis & -.009 & -.079 & -1.756 & .080 \\
IPQ Cyclical timeline & .148 & .088 & 1.843 & .066 \\
IPQ Illness coherence (carer's understanding) & -.135 & -.093 & -1.985 & .048 \\
IPQ Consequences (for carer) & .493 & .273 & 5.158 & $<.001$ \\
IPQ Externalised cause & -.209 & -.124 & -2.762 & .006 \\
CCQ Reflection/relaxation & .280 & .165 & 2.756 & .006 \\
CCQ Positive focus & -.281 & -.107 & -2.037 & .042 \\
CCQ Interpersonal & .190 & .179 & 2.940 & .004 \\
\hline
\end{tabular}

